\title{
Congenital persistent terminal ventricle and filar cyst
}

\author{
Priyanka Jha $\cdot$ Soni C. Chawla
}

Received: 20 July 2008 /Revised: 11 October 2008 / Accepted: 21 November 2008 / Published online: 9 January 2009

(C) The Author(s) 2009. This article is published with open access at Springerlink.com

A baby born prematurely at 34 weeks' gestation had a sallow patch on the sacrum raising suspicion of spinal dysraphism. Physical examination including neurological examination was normal. Spinal US showed undulations and dilatation of the central echo complex at L1 in the conus medullaris consistent with a persistent terminal ventricle (PTV) (Fig. 1, arrow). Spinal US showed a PTV at L1 (Fig. 2, arrowhead) and a fusiform cystic structure in

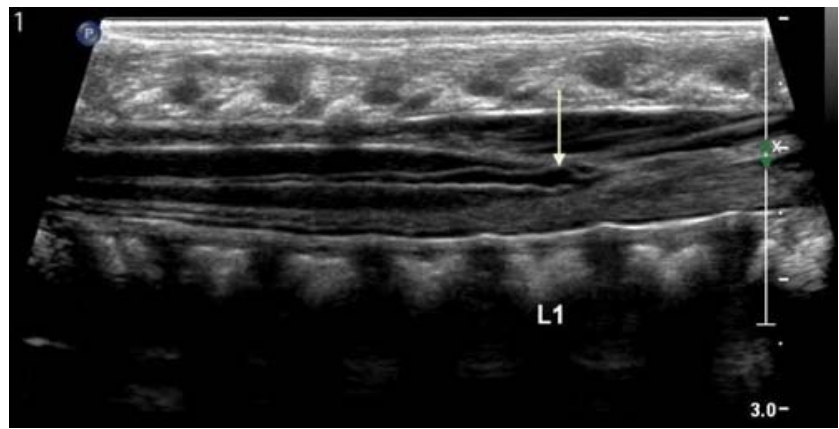

Fig. 1 Persistent terminal ventricle (PTV)

P. Jha

Department of Radiology, San Francisco Medical Center, University of California,

San Francisco, CA, USA

\section{S. C. Chawla $(\square)$}

Department of Radiological Sciences 2D115,

UCLA-Olive View Medical Center,

University of California,

14445 Olive View Drive,

Sylmar, CA 91342, USA

e-mail:schawla@mednet.ucla.edu

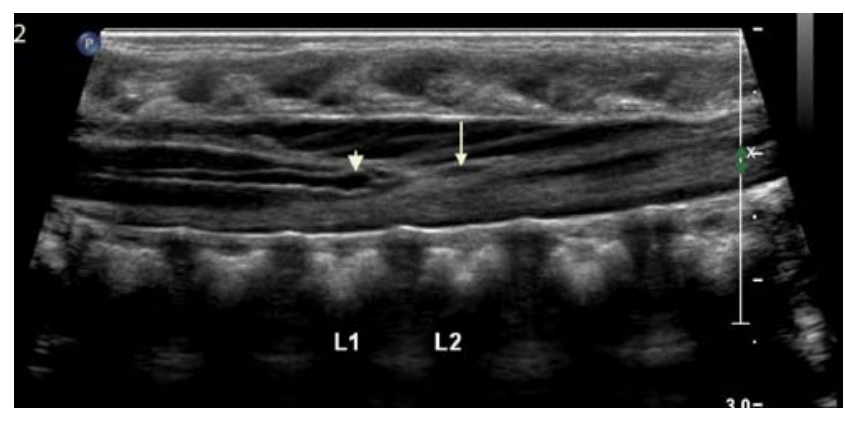

Fig. 2 Coexistent PTV and filar cyst

the filum at L2 consistent with a filar cyst (Fig. 2, arrow). Cranial US was normal. PTV is considered to be in the spectrum of closed spinal dysraphism [1]. Filar cysts are normal variants located in the filum terminale of the cord [2]. These findings help reviewers correctly identify them, alleviating confusion about their location and nomenclature. Such patients can be followed clinically or by US imaging. Symptomatic patients may need to undergo MR imaging.

Open Access This article is distributed under the terms of the Creative Commons Attribution Noncommercial License, which permits any noncommercial use, distribution, and reproduction in any medium, provided the original author(s) and source are credited.

\section{References}

1. Rossi A, Biancheri R, Cama A et al (2004) Imaging in spine and spinal cord malformations. Eur J Radiol 50:177-200

2. Irani N, Goud AR, Lowe LH (2006) Isolated filar cyst on lumbar spine sonography in infants: a case-control study. Pediatr Radiol $36: 1283-1288$ 